\title{
Immunophenotyping of insulitis in control and essential fatty acid deficient mice treated with multiple low-dose streptozotocin
}

\author{
R. B. Fraser ${ }^{1,2}$, G. Rowden ${ }^{2}$, P. Colp ${ }^{2}$, J. R. Wright, Jr ${ }^{1,2,3}$ \\ ${ }^{1}$ Department of Pathology, I.W.K. Grace Health Centre, Halifax, Nova Scotia, Canada \\ ${ }^{2}$ Department of Pathology, Dalhousie University Faculty of Medicine, Halifax, Nova Scotia, Canada \\ ${ }^{3}$ Department of Surgery, Dalhousie University Faculty of Medicine, Halifax, Nova Scotia, Canada
}

Summary Multiple injections of low-dose streptozotocin induce lymphocytic insulitis and autoimmune diabetes in male CD-1 mice. Prior to the onset of insulitis, macrophages infiltrate the islets (single cell insulitis) and presumably help initiate the lymphocytic response directed at streptozotocin-induced neoantigens on islet beta cells. Essential fatty acid deficiency ameliorates the lymphocytic insulitis and prevents diabetes in this model. We hypothesize that essential fatty acid deficiency, which perturbs eicosanoid pathways and blocks the production of inflammatory mediators such as leukotriene $B_{4}$, might prevent or diminish the single cell insulitis and, thus, abrogate the lymphocytic response. The purpose of the study was to determine whether essential fatty acid deficiency causes any differences in the immunophenotype or the time course of single cell insulitis or insulitis after low-dose streptozotocin. Three to five essential fatty acid deficient and 3-5 control mice were treated with low-dose streptozotocin and killed on days $0,3,5,8,10,12$ and 15 . Frozen sections of the pancreata were stained using an immunoperoxidase method with antibodies against mouse macrophages, CD4 T-lymphocytes and CD8 T-lymphocytes. Sections were assessed for the presence and severity of single cell insulitis and insulitis. Based on cell counts in the most severely involved islet from each pancreas, there was no difference in the single cell insulitis in control and essential fatty acid deficient mice. Islets from control pancreata had a higher mean grade of lymphocytic insulitis. These findings suggest that autoimmune diabetes following low-dose streptozotocin in control mice is the result of both lymphocytic and histiocytic infiltrates with subsequent betacell destruction. Our results do not support the hypothesis that the protective effect of essential fatty acid deficiency is due to diminished influx of macrophages into the islets. It is, however, possible that essential fatty acid deficiency deleteriously affects macrophage function and, thus, blunts the lymphocytic response. [Diabetologia (1997) 40: 1263-1268]

Keywords T-lymphocyte, macrophage, insulitis, streptozotocin, essential fatty acid deficiency.
Streptozotocin (STZ), which is a methylnitrosourea with a 2-substituted glucose, is widely used experimentally to induce diabetes mellitus [1]. High-dose STZ induces beta-cell necrosis and diabetes within

Received: 2 June 1997 and in revised form: 11 July 1997

Corresponding author: Dr. R.B.Fraser, M. D., F.R.C.P.C., Department of Pathology, I.W.K. Grace Health Centre, 5850/5980 University Avenue, Halifax, Nova Scotia, B3J 3G9 Canada Abbreviations: STZ, Streptozotocin; LDS, low-dose streptozotocin; EFA, essential fatty acid; EFAD, essential fatty acid deficient, $H \& E$, haematoxylin and eosin.
24-48 h. STZ appears to enter beta cells via the GLUT2 glucose transporter [2] and the mechanism of beta-cell loss appears to be via nicotinamide adenine dinucleotide depletion [3].

In 1976, Like and Rossini [4] demonstrated that multiple subdiabetogenic doses of STZ in male CD1 mice incite a lymphocytic insulitis and autoimmune diabetes that requires several weeks to develop fully. CD-1 mice proved to be particularly susceptible to the diabetogenic effect of low-dose STZ (LDS), while most other mouse strains were resistant or only partially susceptible [1,5-7]. Susceptibility to LDS was initially thought to be determined on a 
genetic basis, but it was later shown that selective immunosuppression directed at suppressor $\mathrm{T}$ cells made resistant strains susceptible. Susceptibility to both insulitis and diabetes could be induced using either cyclophosphamide $(70 \mathrm{mg} / \mathrm{kg})$ intraperitoneally (i.p.) 1 or 6 days before LDS [8], or cyclosporin A subcutaneously $\left(20 \mathrm{mg} \cdot \mathrm{kg}^{-1} \cdot \mathrm{day}^{-1}\right)$ for 2 weeks prior to and simultaneously with the LDS treatments $[9,10]$.

We have previously hypothesized that LDS insulitis and diabetes require five distinct steps [11]: (1) LDS-induced beta-cell "damage" causing neoantigen expression; (2) influx of activated macrophages ("single-cell insulitis") into the damaged islet amplifying the damage by free radical and cytokine production; (3) processing and presentation of beta-cell fragments by activated macrophages; (4) activation of T-helper cells; and (5) lymphocytic infiltration. We believe that susceptible strains like CD-1 pass through all five steps, but that the partially susceptible strains most likely only progress through the first three steps, resulting in less severe and sometimes transient diabetes. However, in these less susceptible strains treated with selective immunosuppression to depress suppressor cell function, insulitis and severe diabetes develop following the progression through all of the five steps.

We have previously shown that essential fatty acid (EFA) deficiency ameliorates insulitis and prevents diabetes in LDS-treated highly susceptible CD-1 mice $[11,12]$ as well as in partially susceptible strains, with or without selective immunosuppression directed at suppressor $\mathrm{T}$ cells [10]. The following study tests the hypothesis that EFA deficiency prevents or diminishes the influx of macrophages (single cell insulitis) into islets after LDS treatment in male CD-1 mice. Immunophenotyping studies were performed on the insular infiltrates in LDS-treated control and EFA deficient (EFAD) mice. The study was designed to determine whether any differences exist in the extent or the time course of the single cell insulitis between EFA deficient and control mice.

\section{Methods and materials}

All studies were performed with the approval of the Dalhousie University Committee on Laboratory Animal Care in accordance with the principles laid down by the Canadian Council on Animal Care. Weanling male CD-1 mice (Charles River, Montreal, Quebec, Canada) were placed on EFA-deficient (Purina 5803C low essential fatty acid purified diet; Purina Test Diets, Richmond, Ind., USA) or control (Agway Prolab 3000 , Syracuse, N. Y., USA) chow for 2 months as in previous studies $[10,11,13,14]$. The EFAD and control mice received LDS (Sigma, St. Louis, Mo., USA) treatment $\left(40 \mathrm{mg} \cdot \mathrm{kg}^{-1}\right.$. day $^{-1}$ i.p. for 5 days). Mice were bled retro-orbitally and tested for hyperglycaemia 3 times per week after LDS treatment as in previous studies. Diabetes was defined as non-fasted plasma glucose levels over $11.1 \mathrm{mmol} / 1$.
Groups of 3-5 control and 3-5 EFAD mice were killed on days $0,3,5,8,10,12$, and 15 . Pancreata were removed, snap frozen in OCT mounting medium (Tissue-Tek 4583; Miles, Elkhart, Ind., USA) and stored at $-80^{\circ} \mathrm{C}$. Serial frozen sections were cut and mounted on silinated slides. Slides were then fixed in cold $\left(-20^{\circ} \mathrm{C}\right)$ acetone for $2 \mathrm{~min}$, air-dried and stored in sealed slide boxes at $-20^{\circ} \mathrm{C}$. Care was taken to avoid freezing and thawing of the slides. Frozen sections were stained with haematoxylin and eosin $(\mathrm{H} \& \mathrm{E})$ as well as by direct immunoperoxidase using antibodies against mouse macrophages (MOMA-2 and F4/80; Serotec Canada, Mississauga, Ontario, Canada), CD8+ T-lymphocytes (YTS 169.4; Cedarlane Laboratories Limited, Hornby, Ontario, Canada) and CD4+ Tlymphocytes (YTS 191.1; Cedarlane Laboratories). Immunoperoxidase staining was performed as previously described [15].

The total number of islets was counted in each section. Insulitis was graded on the H\&E stained slides according to previously published methods [11]. Briefly, all pancreata were assigned a grade using the following scheme: (0) normal (i.e. no inflammation), (1) peri-ductal lymphocytic infiltrates (i.e. lymphocytic infiltrate at ductal pole of islet only), (2) peri-insulitis (i.e. lymphocytic infiltrate surrounding but not invading islets), (3) insulitis (i.e. lymphocytic infiltrate invading islets), and (4) severe insulitis (i.e. massive lymphocytic infiltrate with islet destruction). Pancreata were graded for insulitis on the basis of the most severely involved islet in each pancreas. Immunoperoxidase stains were examined along with the appropriate positive and negative controls. Semi-quantitative analysis was performed on F4/80-stained sections and cell counts performed on the most heavily involved islet in each section. Five grades of macrophage infiltration were based on the number of F4/80-positive cells in or around the islet. The grading scheme was as follows: 0 ( $0-3$ cells), 1 ( $4-10$ cells), 2 (11-20 cells), 3 (21-50 cells) and 4 (> 50 cells).

Sections stained with antibodies to CD4 or CD8 were also examined semi-quantitatively. Five grades of lymphocytic infiltration were based on numbers of CD4-positive or CD8-positive cells in or around islets. The grading scheme was the same as for macrophages except that it is normal to have occasional tissue macrophages but not lymphocytes in non-inflamed islets. Therefore, the grading scheme was modified as follows: 0 ( 0 cells), 1 (1-10 cells), 2 (11-20 cells), 3 (21-50 cells), and 4 (>50 cells).

\section{Results}

EFA deficiency prevented diabetes in LDS treated mice (data not shown) as in all previous studies [10, $11,12]$. Frozen sections of pancreata from all mice contained multiple islets, usually between four and 12. As shown in Table 1, there was no evidence of peri-insulitis or insulitis in H\&E-stained sections of pancreata from either control or EFAD mice until day-10 post LDS treatment. On days 10, 12 and 15, peri-insulitis or insulitis was seen in both groups with higher grade infiltrates seen in the control mice in each instance (pooled data, $t$-test: $t=2.38, d f=19$, $p=0.028$ ). In general, pancreata from control mice usually showed insulitis while those from EFAD mice usually showed peri-insulitis.

Table 2 shows the relative number of macrophages, CD4-positive T cells and CD8-positive T cells in 
Table 1. Grading of lymphocytic insulitis in LDS treated control and EFAD mice

\begin{tabular}{lcccccc}
\hline & Day & & & & & \\
\cline { 2 - 6 } & 0 & 3 & 5 & 8 & 10 & 12 \\
\hline $\begin{array}{l}\text { Insulitis } \\
\begin{array}{l}\text { EFAD mice } \\
\text { Insulitis }\end{array}\end{array}$ & 0 & 0 & 0 & 0 & $3 \pm 0$ & $3.20 \pm 0.84$ \\
\hline
\end{tabular}

Data are mean \pm SD

Table 2. Immunohistochemical grading of lymphocytic and macrophage infiltration in LDS treated control and EFAD mice

\begin{tabular}{|c|c|c|c|c|c|c|c|}
\hline & \multicolumn{7}{|c|}{ Day } \\
\hline & 0 & 3 & 5 & 8 & 10 & 12 & 15 \\
\hline $\begin{array}{l}\text { Control mice } \\
\text { Macrophage } \\
\text { CD4 } \\
\text { CD8 }\end{array}$ & $\begin{array}{l}0 \\
0 \\
0\end{array}$ & $\begin{array}{l}0.67 \pm 0.58 \\
0 \\
0\end{array}$ & $\begin{array}{l}0 \\
0 \\
0\end{array}$ & $\begin{array}{l}1.67 \pm 0.58 \\
0.67 \pm 0.58 \\
1.33 \pm 0.58\end{array}$ & $\begin{array}{l}0.67 \pm 1.15 \\
0.67 \pm 1.15 \\
1.00 \pm 1.00\end{array}$ & $\begin{array}{l}2.60 \pm 1.30 \\
0.80 \pm 0.84 \\
1.40 \pm 0.89\end{array}$ & $\begin{array}{l}2.50 \pm 0.71 \\
2.00 \pm 0.00 \\
1.67 \pm 0.58\end{array}$ \\
\hline $\begin{array}{l}\text { EFAD mice } \\
\text { Macrophage } \\
\text { CD4 } \\
\text { CD8 }\end{array}$ & $\begin{array}{l}0 \\
0 \\
0\end{array}$ & $\begin{array}{l}0.33 \pm 0.58 \\
0 \\
0\end{array}$ & $\begin{array}{l}0 \\
0 \\
0\end{array}$ & $\begin{array}{l}1.00 \pm 0.00 \\
0 \\
0\end{array}$ & $\begin{array}{l}1.50 \pm 0.71 \\
1.00 \pm 0.00 \\
1.00 \pm 1.41\end{array}$ & $\begin{array}{l}3.00 \pm 0.00 \\
1.40 \pm 1.14 \\
2.00 \pm 0.71\end{array}$ & $\begin{array}{l}2.67 \pm 1.53 \\
1.67 \pm 1.15 \\
1.33 \pm 1.53\end{array}$ \\
\hline
\end{tabular}

Data are mean \pm SD

and around islets at various times after LDS treatment. Prior to the onset of insulitis on day 10 (Table 1), small numbers of macrophages surrounded and infiltrated the pancreatic islets in both control and EFAD groups (Fig. 1). Although the magnitude of these infiltrates increased with time throughout the study, there was never any difference between the control and EFAD groups at any time interval ( $t$ test, N.S.). Immunohistochemical analysis of insulitis in both control and EFAD mice demonstrated the inflammatory cell infiltrate to be composed of roughly equal numbers of CD4-positive lymphocytes, CD8positive lymphocytes, and macrophages. Lymphocytic infiltrates, both CD4 and CD8, were seen earlier in control than EFAD mice (Table 2), but EFA deficiency did not significantly alter the numbers of CD4 or CD8-positive cells compared to controls on days 10,12 or 15 .

\section{Discussion}

In 1976, Like and Rossini [4] described the LDS model for autoimmune diabetes; based on routine histology, the bulk of the insular infiltrate in LDS-treated CD-1 mice appeared to be lymphocytes. Herald et al. [16] and Kantwerk et al. [17] demonstrated with immunohistochemistry large numbers of CD4-positive and CD8-positive cells. Later, Kolb-Bachofen et al. [18] demonstrated that, prior to onset of insulitis and diabetes, macrophages infiltrated the islets and they termed this "single cell insulitis". The same group also demonstrated that single cell insulitis played an important role in the onset of LDS diabetes by demonstrating that treatment with silica, a macrophage toxin, was more protective than T-cell depletion [19]. These findings, along with Leiter's [20] observations on LDS-treated SCID mice, implicated the macrophage in the early onset of LDS diabetes in mice. SCID mice, which have no functional T- or B-lymphocytes but normal numbers of natural killer cells, macrophages and granulocytes, did not develop lymphocytic insulitis but showed a moderate sensitivity to the diabetogenic effects of LDS. These mice developed diabetes with the onset requiring several weeks rather than several days, as might be expected if only due to the cumulative cytotoxic effects of the LDS.

Wright et al. [12] demonstrated that essential fatty acid (EFA) deficiency ameliorated insulitis and prevented diabetes in LDS-treated male CD-1 mice [12]. In that study, control mice developed severe diabetes with marked insulitis noted histologically at autopsy. There was both lymphocytic infiltration into the islets and extensive beta-cell loss. EFAD mice remained normoglycaemic $(12 / 13)$ or developed only mild diabetes (1/13), with focal mild peri-insulitis and negligible beta-cell degranulation. The control mice had a mean plasma glucose level of $22.2 \mathrm{mmol}$ while EFAD mice averaged $7.2 \mathrm{mmol}$. However, EFAD mice developed severe diabetes following a single intravenous injection of "high dose" STZ suggesting that EFA deficiency did not protect from the direct toxicity of STZ, but only the diabetogenic effects of LDS. 

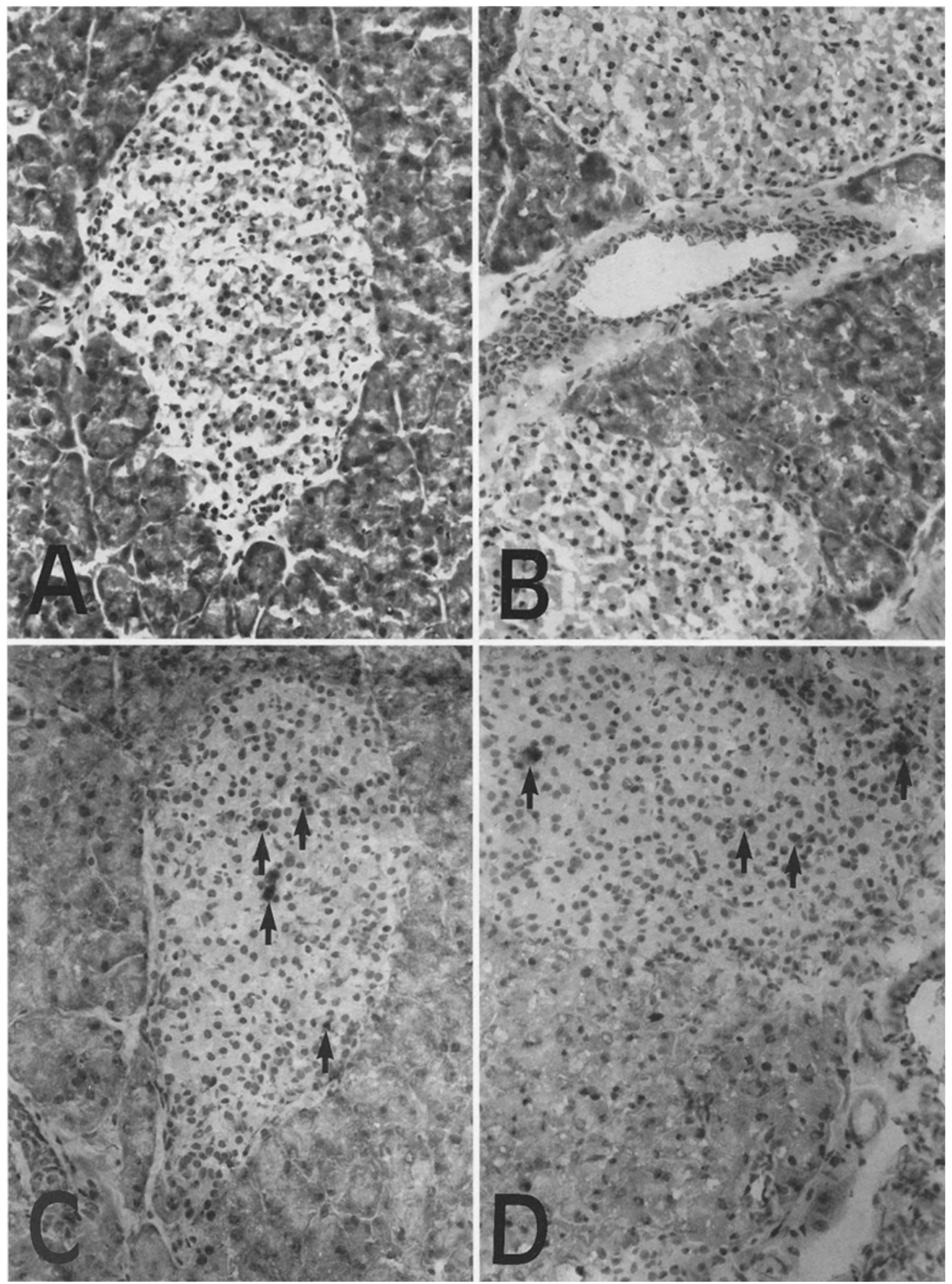

Fig.1. A-D Histology of islet tissue from control $(\mathbf{A}, \mathbf{C})$ and EFAD (B, D) mice treated with LDS and killed at day 3 . $\mathbf{A}$ and $\mathbf{B}$ are sections stained with $\mathrm{H} \& \mathrm{E}$ and show normal islet architecture with no evidence of a lymphocytic infiltrate (insulitis). $\mathbf{C}$ and $\mathbf{D}$ are immunoperoxidase stained sections using F4/80 against macrophages (positively stained cells indicated by arrows); note there is no difference in the magnitude of this "single cell insulitis" in control (C) and EFAD (D) islets. $200 \times$
The protective effect of EFA deficiency cannot be directed primarily at the lymphocytic insulitis because EFA deficiency prevents diabetes in partially susceptible strains which develop milder, sometimes transient diabetes and do not develop significant lymphocytic insulitis [10]. Therefore, the influx and activation of macrophages alone appears to be weakly diabetogenic in these strains following LDS treatment. In these less susceptible mouse strains, we 
speculate that the protective effect is exerted at the single cell insulitis (i.e. step 2, see above) and that EFA deficiency blocks the influx and activation of macrophages into the LDS-damaged islets.

Clearly, the immune system of LDS-treated mice recognize only LDS-modified islets. This statement is supported by the observation that islet isografts performed 2 weeks after the first LDS treatment do not incite a lymphocytic infiltrate even though insulitis is still progressing in the native islets of the pancreas $[21,22]$. It has been shown, however, that islets treated in vitro with LDS and subsequently isografted into LDS-treated diabetic mice with active insulitis were destroyed [22]. It, therefore, seems likely that LDS treatment modifies islets to become antigenic (i.e. step 1). The exact nature of the LDS-induced beta-cell neoantigen is unknown; clearly, EFA deficiency does not prevent neoantigen formation since injections of $99 \%$ pure methyl linoleate (EFA repletion) 3 days after LDS precipitates a $100 \%$ incidence of insulitis and diabetes in EFAD mice [12]; however, EFA supplementation must occur within a brief window of susceptibility [11]. The observation that delayed repletion does not cause diabetes suggests that the protective effect of EFA deficiency is exerted prior to T-cell involvement since presumably immune "memory" occurs during steps 4 and 5 [11].

It is well-documented that EFA deficiency markedly diminishes leukotriene B4 production [23] and, therefore, inhibits the influx of leukocytes in response to inflammatory stimuli [24]. It is logical to speculate that EFA deficiency might prevent or ameliorate the single cell insulitis. In the absence of EFA deficiency, the LDS damage may be amplified by the influx of activated macrophages (single cell insulitis). Islets possess low levels of free radical scavenging enzymes and are, therefore, susceptible to damage by free radicals released by the activated macrophages [ 25 , 26]. In addition, these activated macrophages release monokines such as interleukin- 1 and tumour necrosis factor which are also cytotoxic to islets [27]. Both the free radical damage and the release of the monokines could amplify beta-cell damage which could result in a cascade effect attracting and activating more macrophages. These findings are supported by our observation that desferrioxamine, a hydroxyl radical scavenger, administered $5 \mathrm{~h}$ after the last LDS injection prevents LDS-induced insulitis and diabetes [28].

The results of our current study confirm the findings of others who have reported that LDS-induced insulitis is characterized by both lymphocytic and histiocytic infiltrates and that the latter precedes the former [16-18]. Our study also confirms our previous observation that EFA deficiency decreased the severity of lymphocytic insulitis in LDS-treated mice $[10,11,12]$. Although our study was designed primarily to examine the earliest aspect of the LDS insulitis process (i.e. macrophage migration rather than lymphocytic infiltration), we can make a few observations pertaining to the latter. Lymphocytic infiltration could not be seen on H\&E sections until day 10. Based on immunohistochemical staining, CD4 and CD8-positive cells infiltrated islets earlier in control (i.e. day 8) than in EFAD mice (i.e. day 10); however, no statistically significant decrease in either T-cell population was observed in EFAD mice on days 10,12 , or 15 . Based on the results of prior studies in which EFA deficiency markedly decreased the severity of insulitis (including the quantity of the lymphocytic infiltrates) in CD-1 mice killed at 26-28 days post LDS [11, 12], we would expect that the numbers of T cells would be less in EFAD than control mice at later time intervals. Nevertheless, even in these early intervals, the mean insulitis score was significantly less reflecting that peri-ductal infiltrates and peri-insulitis were more frequent in EFAD mice while insulitis was more frequent in control mice. There were no statistically significant differences between numbers of CD4 and CD8 positive cells infiltrating in and around the islets of control or EFAD mice at any interval. This is consistent with the 10-day post-LDS results of Kantwerk et al. [17].

Our results do not support our primary hypothesis that the protective effect of EFA deficiency is due to diminished influx of macrophages into the islets since no difference in single cell insulitis was apparent in the pancreata of EFAD compared to control mice. It is, however, possible that EFA deficiency deleteriously affects macrophage function, possibly affecting cytokine production. EFA deficiency also has a generalized inhibitory affect on eicosanoid metabolism and it is possible that this diminishes the response to LDS in some unknown way. Regardless of the poorly understood mechanism of action, EFA deficiency has a marked protective effect in the LDS model of autoimmune type 1 diabetes mellitus and this protective effect is also seen in spontaneously diabetic BB Wistar rats [29-31].

Acknowledgements. This study was supported by the I.W.K. Grace Research Foundation and by a grant from the Canadian Diabetes Association in honour of Marion C. Dill.

\section{References}

1. Wilson GL, Leiter EH (1990) Streptozotocin interactions with pancreatic B cells and the induction of insulin-dependent diabetes. Curr Top Microbiol Immunol 156: 27-54

2. Schnedl WJ, Ferber S, Johnson JH, Newgard CB (1994) STZ transport and cytotoxicity - specific enhancement in GLUT2-expressing cells. Diabetes 43: 1326-1333

3. Okamoto H (1985) Molecular basis of experimental diabetes: degeneration, oncogenesis, and regeneration of pancreatic B-cells of islets of Langerhans. Bioessays 2: 15-21

4. Like AA, Rossini AA (1976) Streptozotocin-induced pancreatic insulitis: new model of diabetes mellitus. Science 193: $415-417$ 
5. Kolb H (1987) Mouse models of insulin dependent diabetes mellitus: low-dose streptozotocin-induced diabetes and nonobese diabetic (NOD) mice. Diabetes Metab Rev 3: 751-778

6. Kolb H, Kröncke KD (1993) Lessons from the low-dose streptozotocin model in mice. Diabetes Rev 1: 116-126

7. Rossini AA, Appel MC, Williams RM, Like AA (1977) Genetic influence of the streptozotocin-induced insulitis and hyperglycemia. Diabetes 26: 916-920

8. Kiesel U, Greulich B, Moume CM-S, Kolb H (1981) Induction of experimental autoimmune diabetes by low-dose streptozotocin treatment in genetically resistant mice. Immunol Letters 3: 227-230

9. Weide L, Lacy P, Smith H, Tung K (1991) Adoptive transfer of low-dose streptozotocin autoimmune diabetes in a nonsusceptible strain. Diabetes 40 [Suppl 1]: 56A (Abstract)

10. Wright JR Jr, Fraser RB, Kapoor S, Cook HW (1995) Essential fatty acid deficiency prevents multiple low-dose streptozotocin-induced diabetes in naive and cyclosporintreated low-responder murine strains. Acta Diabetol 32: 125-130

11. Wright JR Jr, Haliburton B, Russell H, Henry M, Fraser R, Cook HW (1991) The anti-diabetogenic effect of essential fatty acid deficiency in multiple low-dose streptozotocintreated mice persists if essential fatty acid repletion occurs outside a brief window of susceptibility. Diabetologia 34 : 709-714

12. Wright JR Jr, Lefkowith JB, Schreiner G, Lacy PE (1988) Essential fatty acid deficiency prevents multiple low-dose streptozotocin-induced diabetes in CD-1 mice. Proc Natl Acad Sci USA 85: 6137-6141

13. Lawen JG, Wright JR Jr, Yu W, Epstein HR (1991) Donor essential fatty acid deficiency does not prolong heterotopic cardiac allograft survival in rats. Transplantation 52: 178180

14. Lawen JG, Yu W, Cook HW, Wright JR Jr (1993) The failure of donor essential fatty acid deficiency to prevent renal allograft rejection in rats. Transplantation 56: 1269-1270

15. Rowden G (1984) Antigenic markers of epidermal Langerhans cells. In: Skerrous D, Skerrous CJ (eds) Methods in skin research. John Wiley and Sons, New York, pp 91-144

16. Herald KC, Montag AG, Fitch FW (1987) Treatment with anti-T-lymphocyte antibodies prevents induction of insulitis in mice given multiple doses of streptozotocin. Diabetes 36: 796-801

17. Kantwerk G, Cobbold S, Waldmann H, Kolb H (1987) L3T4 and Lyt-2 T cells are both involved in the generation of low-dose streptozotocin-induced diabetes in mice. Clin Exp Immunol 70: 585-592

18. Kolb-Bachofen V, Epstein S, Kiesel U, Kolb H (1988) Lowdose streptozotocin-induced diabetes in mice: electron microscopy reveals single cell insulitis before diabetes onset. Diabetes 37: 21-27

19. Oschilewski M, Schwab E, Kiesel U et al. (1986) Administration of silica or monoclonal antibody to Thy-1 prevents low-dose streptozotocin-induced diabetes in mice. Immunol Lett 12: 289-294

20. Leiter EH (1985) Differential susceptibility of $B A L B / c$ sublines to diabetes induction by multi-dose streptozotocin treatment. Curr Top Microbiol Immunol 122: 78-85

21. Andersson A (1979) Islet implantation normalizes hyperglycaemia caused by streptozotocin-induced insulitis: experiments in mice. Lancet 1: 581-584

22. Weide L, Lacy P (1991) Low-dose streptozotocin-induced autoimmune diabetes in an islet transplantation mode. Diabetes 40: 1157-1162

23. Lefkowith JB (1988) Essential fatty acid deficiency inhibits the in vivo generation of leukotriene B4 and suppresses levels of resident and elicited leukocytes in acute inflammation. J Immunol 140: 228-233

24. Schreiner GF, Rovin B, Lefkowith JB (1989) The anti-inflammatory effects of essential fatty acid deficiency in experimental glomerulonephritis. The modulation of macrophage migration and eicosanoid metabolism. J Immunol 143: 3192-3199

25. Malaisse WJ, Malaisse-Lagae F, Sener A, Pipeleers DG (1982) Determinants of the selective toxicity of alloxan to the beta cell. Proc Natl Acad Sci USA 79: 927-930

26. Grankvist K, Marklund SL, Taljedal I-B (1981) CuZn-superoxide dismutase $\mathrm{MN}$-superoxide dismutase, catalase, and glutathione peroxidase in pancreatic islets and other tissues of the mouse. Biochem J 199: 393-398

27. Mandrup-Poulsen T, Helqvist S, Wogensen LD et al. (1990) Cytokines and free radicals as effector molecules in the destruction of pancreatic beta cells. Curr Top Microbiol Immunol 164: 169-193

28. Mendola J, Wright JR Jr, Lacy PE (1989) Oxygen free-radical scavengers and immune destruction of murine islets in allograft rejection and multiple low-dose streptozotocin-induced insulitis. Diabetes 38: 379-385

29. Schreiner G, Rossini A, Mordes J et al. (1988) Essential fatty acid deficiency inhibits the development of diabetes in rats. Diabetes 37 [Suppl 1]: 80A (Abstract)

30. Lenrow D, Luketich J, Naji A, Barker C (1989) Immune modulation of the BB rats by essential fatty acid deficient (EFAD) diet. Diabetes 38 [Suppl 2]: 74A (Abstract)

31. Lefkowith J, Schreiner G, Cormier J et al. (1990) Prevention of diabetes in the BB rat by essential fatty acid deficiency: relationship between physiological and biochemical changes. J Exp Med 171: 729-743 